\title{
Co-administration of NVP-AEW541 and dasatinib induces mitochondrial-mediated apoptosis through Bax activation in malignant human glioma cell lines
}

\author{
DANIEL R. PREMKUMAR ${ }^{1}$, ESTHER P. JANE ${ }^{1}$ and IAN F. POLLACK ${ }^{1,2}$ \\ ${ }^{1}$ Department of Neurosurgery, University of Pittsburgh School of Medicine; \\ ${ }^{2}$ University of Pittsburgh Cancer Institute Brain Tumor Center, Pittsburgh, PA 15201, USA \\ Received April 7, 2010; Accepted May 18, 2010 \\ DOI: 10.3892/ijo_00000712
}

\begin{abstract}
Glioblastoma multiforme represents a largely incurable tumor for which novel therapeutic strategies are required. We report the effect of NVP-AEW541, an inhibitor of insulin-like growth factor-I receptor (IGF-IR) kinase activity on growth and signaling in a panel of glioma cell lines. NVP-AEW541 blocked phosphorylation of IGF-IR in a dose- and time-dependent manner and inhibited proliferation and clonogenicity with median effective concentrations of 2.5-10 $\mu \mathrm{M}$. NVP-AEW541 also induced loss of mitochondrial membrane potential and release of cytochrome $\mathrm{c}$ and apoptosis-inducing factor (AIF) from mitochondria. Because concentrations of NVP-AEW541 required to significantly inhibit glioma cell viability and downstream signaling also inhibited non-neoplastic astrocytes, we questioned whether differential efficacy could be enhanced by combination with inhibition of other tyrosine kinases dysregulated in gliomas. Dasatinib was selected as a combination agent based on its distinct inhibitory profile for other relevant signaling targets. Combined treatment with NVP-AEW541 and dasatinib induced significantly more apoptosis than either agent alone in glioma cells, but not non-neoplastic astrocytes, and synergistically inhibited clonogenic survival. Mechanistic studies indicated that combination of NVP-AEW541 and dasatinib significantly reduced pERK and pAkt and markedly increased AIF release, Bax oligomerization and loss of mitochondrial potential compared to each agent alone. Overexpression of Bcl-2 and Akt significantly attenuated NVP-AEW541 and dasatinib-induced Bax activation and cell death. Our data indicate that activation of Bax plays a critical role in mediating NVP-AEW541 and dasatinib-induced apoptosis, and suggest the potential value of combining IGFR inhibition with other classes of tyrosine kinase inhibitors to potentiate therapeutic efficacy.
\end{abstract}

Correspondence to: Dr Ian F. Pollack, Department of Neurosurgery, Children's Hospital Drive, 45th Street and Penn Avenue, Pittsburgh, PA 15201, USA

E-mail: ian.pollack@chp.edu

Key words: glioma, NVP-AEW541, dasatinib, Bax, apoptosis

\section{Introduction}

Deregulated growth in cancer is not solely due to an increase in proliferation but is also to an alteration in the balance between proliferation and apoptosis (1). Malignant gliomas characteristically have dysregulation of multiple growth signaling and apoptosis resistance pathways. Epidermal growth factor receptor (EGFR), insulin-like growth factor receptor (IGF-IR), and platelet-derived growth factor receptor (PDGFR), among others, have been implicated in glial tumorigenesis (2). To date, therapeutic trials for these tumors have focused on EGFR and PDGFR, but comparatively little attention has been focused on strategies to block IGFR. Ligandbound IGF-IR interacts with insulin receptor substrates (IRS) 1 and 2, which in turn become phosphorylated on tyrosine residues and recruit $\mathrm{SH} 2$ domain-containing signaling molecules (3), activating MAPK/ERK and Akt signaling, and promoting a number of processes in cancer cells, including proliferation, survival, metastasis and invasion (4). Moreover, increased IGF-1R signaling has been implicated in resistance of NSCLC, breast cancer and prostate cancer cells to the EGFR inhibitors, erlotinib and gefitinib $(5,6)$.

Although inhibition of the IGF-IR by a variety of strategies has shown independent activity in hematologic and solid tumors in vitro and in vivo $(7,8)$, combined targeting of IGF-1R and ErbB receptors with dominant negative constructs, antibodies, or small molecule inhibitors has shown improved effects on inhibition of cell growth relative to single agents (9). Combinations of IGF-1R and EGFR inhibitory antibodies have also shown improved activity in A549 xenografts relative to individual agents (10). In addition, a non-selective IGF-1R kinase inhibitor, AG1024, enhanced the ability of gefitinib or erlotinib to block proliferation and induce apoptosis of breast cancer (11) and hepatoma cells (12).

Antibodies that target IGF-1R and several small molecule IGF-1R inhibitors are in preclinical or early clinical development (4). NVP-AEW541, is a small molecule IGF-1R inhibitor that belongs to the pyrrolo[2,3-d]pyrimidine class, and was identified as a selective inhibitor of IGF-IR kinase activity (13). NVP-AEW541 had a potent cytotoxic effect on multiple myeloma cells in vitro and in vivo (7). In addition, NVPAEW541 potentiated the action of other agents, such as bortezomib, lenalidomide, dexamethasone or melphalan (7). 
Mechanistic studies indicated that NVP-AEW541 provoked cell cycle blockade accompanied by $\mathrm{pRb}$ downregulation, increased levels of p27, and reduction in CDK2 activity. Finally, NVP-AEW541 induced cell death through caspasedependent and -independent mechanisms. Moreover, analyses on the mechanisms of IGF-IR inhibitors antiproliferative effect indicate that these compounds may act by blocking cell cycle progression and inducing cell death (14). All these data, suggest the potential effect of IGF-IR kinase inhibitors as therapeutic agents.

We therefore examined the efficacy of NVP-AEW541 against a series of glioma cell lines. Although we found that in vitro proliferation and clonogenic growth of glioma cells were greatly reduced by treatment with NVP-AEW541 concentrations in the low micromolar range, apoptosis was only seen with concentrations that also induced toxicity in non-neoplastic astrocytes. We questioned whether combining IGFR inhibition with blockade of several other tyrosine kinases implicated in glioma growth would enhance efficacy and apoptotic signaling.

Src regulates signals from multiple cell surface molecules. In malignant cells, c-Src activation can mediate transformation, proliferation, survival, angiogenesis and motility (15). In that context, BMS-354825 (dasatinib) is a small molecule inhibitor effective in combating malignancies characterized by aberrant activation of c-Src, BCR-ABL, KIT, and EGFR by interfering with receptor phosphorylation (16). Activity has been observed in chronic myelogenous leukemia, pancreatic adenocarcinoma, colon cancer, prostate cancer, non-small cell lung cancer and breast malignancies (17-22). Recently, Milano et al (23) showed antiproliferative effects in glioma cell lines, although this agent did not induce apoptotic cell death.

Based on these observations, we examined the therapeutic efficacy of combining NVP-AEW541 with dasatinib. These studies demonstrated synergistic antiproliferative and proapoptotic effects. The latter was associated with enhanced cytochrome $\mathrm{c}$ release, activation of Bax and mitochondrial injury suggesting the involvement of the intrinsic cell death pathway. These data suggest that combining NVP-AEW541 and with other classes of tyrosine kinase inhibitors may provide significantly improved therapeutic efficacy against malignant human glioma compared to the use of either strategy alone.

\section{Materials and methods}

Inhibitors and reagents. NVP-AEW541 was kindly provided by Dr F. Hofmann (Novartis Inc., Switzerland). Dasatinib was purchased from Chemie Tek (Indianapolis, IN). Human recombinant epidermal growth factor was purchased from Cell Signaling Technology, Inc. (Beverly, MA); Platelet derived growth factor from R\&D Systems, Inc. (Minneapolis, $\mathrm{MN})$.

Cell culture. The established malignant glioma cell lines U87, T98G, U373, LN229 and A172 were obtained from the American Type Culture Collection (Manassas, VA). LN18 and LNZ308 was generously provided by Dr Nicolas de Tribolet. U87, T98G and U373 were cultured in growth medium composed of minimum essential medium supplemented with sodium pyruvate and non-essential amino acids; LN18, LN229, A172 and LNZ308 were cultured in $\alpha$-minimal essential medium supplemented with L-glutamine. Human astrocytes (HA) and human cerebellar astrocytes (HAC) were obtained from ScienCell Research Laboratories (San Diego, CA) and cultured in astrocyte growth media. All growth media contained $10 \%$ fetal calf serum, L-glutamine, ribonucleosides, deoxynucleosides, $100 \mathrm{IU} / \mathrm{ml}$ penicillin, $100 \mathrm{mg} / \mathrm{ml}$ streptomycin and $0.25 \mathrm{mg} / \mathrm{ml}$ amphotericin (Invitrogen, Carlsbad, CA). These cell lines were chosen because they are widely available and incorporate, in various combinations, a range of genomic alterations commonly seen in malignant gliomas. Cells were grown in $75-\mathrm{cm}^{2}$ flasks at $37^{\circ} \mathrm{C}$ in a humidified atmosphere with $5 \%$ carbon dioxide and were subcultured every 4-7 days by treatment with $0.25 \%$ trypsin in Hanks' balanced salt solution (Invitrogen).

Cell proliferation and cytotoxicity assays. Cells ( $5 \times 10^{3} /$ well) were plated in 96-well microtiter plates (Costar, Cambridge, MA) in $100 \mu \mathrm{l}$ of growth medium, and after overnight attachment, were exposed for 3 days to a range of concentrations of inhibitors, alone and in combination. Control cells received vehicle alone (DMSO). After the treatment interval, cells were washed in inhibitor-free medium, and the number of viable cells was determined using a colorimetric cell proliferation assay (CellTiter96 Aqueous non-radioactive cell proliferation assay; Promega, Madison, WI) (24,25). All studies were conducted in triplicate and repeated at least three times independently. To perform the assay, $20 \mu 1$ of MTS/phenazine methosulfate solution was added to each well, and after $1 \mathrm{~h}$ of incubation at $37^{\circ} \mathrm{C}$ in a humidified $5 \%$ $\mathrm{CO}_{2}$ atmosphere, absorbance was measured at $490 \mathrm{~nm}$ in a microplate reader. Triplicate wells with predetermined cell numbers were subjected to the above-mentioned assay in parallel with the test samples to normalize the absorbance readings. To assess cellular toxicity, $2.5 \times 10^{5}$ cells were seeded in 6-well dishes and on the following day, treated with selected concentrations of inhibitors or vehicle. Cells were harvested, stained with trypan blue, and counted using a hemacytometer. All samples were tested in triplicate. Viable (trypan blue-excluding) and dead cell numbers were plotted as a function of inhibitor concentration.

Clonogenic growth assay. The effect of different inhibitor concentrations on cell viability was also assessed using a clonogenic assay. For this analysis, 250 cells were plated in 6-well trays in growth medium, and after overnight attachment, cells were exposed to selected inhibitor concentrations or vehicle for 1 or 2 days. The cells were then washed with inhibitor-free medium and allowed to grow for 2 weeks under inhibitor-free conditions. Colonies of a diameter of $\sim 2-4 \mathrm{~mm}$ were counted directly. All studies were performed in triplicate.

Transient transfection. Empty vector, pcDNA3 was from Dr Michael Greenberg (Harvard Medical School, Boston, MA). The expression vectors pcDNA3-Bcl-2 was obtained from Dr Stanley Korsmeyer (Dana Farber Cancer Institute, Boston, MA). pcDNA3-Myr-HA-Akt1 was obtained from Dr William Sellers (Dana Farber Cancer Institute). Malignant human glioma cell lines were plated in $10-\mathrm{cm}$ plates and main- 
tained in complete media and kept at $37^{\circ} \mathrm{C}$ in a humidified $5 \% \mathrm{CO}_{2}$ incubator. Transient transfection was performed at 60-70\% confluence using FuGENE 6 (Roche) according to the manufacturer's recommendations. The total amount of transfected DNA was maintained at $5 \mu \mathrm{g}$. After a $36-\mathrm{h}$ transfection period, cells were treated with or without inhibitors for an additional $24 \mathrm{~h}$. Control cells received equal amount of DMSO.

Western blotting analysis. Treated and untreated cells were washed in cold PBS and lysed in buffer containing $30 \mathrm{mM}$ HEPES, 10\% glycerol, 1\% Triton X-100, $100 \mathrm{mM} \mathrm{NaCl}$, $10 \mathrm{mM} \mathrm{MgCl} 2,5 \mathrm{mM}$ EDTA, $2 \mathrm{mM} \mathrm{Na} \mathrm{VO}_{4}, 2 \mathrm{mM}$ ß-glycerophosphate, $1 \mathrm{mM}$ phenylmethylsulfonyl fluoride, $1 \mathrm{mM}$ 4-(2-aminoethyl)benzenesulfonyl fluoride, $0.8 \mu \mathrm{M}$ aprotinin, $50 \mu \mathrm{M}$ bestatin, $15 \mu \mathrm{M}$ E-64, $20 \mu \mathrm{M}$ leupeptin, and $10 \mu \mathrm{M}$ pepstatin A for $15 \mathrm{~min}$ on ice. Samples were centrifuged at $12,000 \mathrm{x} \mathrm{g}$ for $15 \mathrm{~min}$, supernatants were isolated, and protein was quantified using Protein Assay Reagent (Pierce Chemical, Rockford, IL). Equal amounts of protein were separated by SDS-polyacrylamide gel electrophoresis (PAGE) and electrotransferred onto a nylon membrane (Invitrogen). Nonspecific antibody binding was blocked by incubation of the blots with $2 \%$ bovine serum albumin in Tris-buffered saline (TBS)/Tween-20 $(0.1 \%)$ for $1 \mathrm{~h}$ at room temperature. The blots were then probed with appropriate dilutions of primary antibody overnight at $4^{\circ} \mathrm{C}$. Unless otherwise mentioned all antibodies used for Western blot analysis were purchased from Cell Signaling Technology, Inc. The antibody-labeled blots were washed three times in TBS/Tween-20 for $15 \mathrm{~min}$ and then incubated with a 1:1500 dilution of horseradish peroxidase-conjugated secondary antibody (Santa Cruz Biotechnology, Inc.) in TBS/Tween-20 at room temperature for $1 \mathrm{~h}$. After additional washing in TBS/Tween 20, the proteins were visualized by Western blot chemiluminescence reagent (CST). Where indicated, the blots were reprobed with antibodies against $B$-actin (Sigma Aldrich, St. Louis, MO) to ensure equal loading and transfer of proteins. Primary antibodies to phospho IGF-1R, and total IGF-1R; phosphoSrc phospho-EGFR (Tyr845), and total EGFR; and phosphoPDGFR- $\beta$ (Tyr751) total PDGFR; were obtained from BioSource International (Camarillo, CA). Scanning densitometry was performed on Western blots using acquisition into Adobe Photoshop (Adobe Systems, Inc., San Jose, CA) and analyzed by image program (UN-SCAN-IT gel ${ }^{\mathrm{TM}}$, version 6.1, Silk Scientific, Utah).

Immunofluorescence and assessment of apoptotic events. T98G cells were plated in chamber culture slides (BD Falcon, Bedford, MA). After overnight incubation, cells were treated and fixed in phosphate-buffered saline (PBS) containing 4\% formaldehyde, and then stained with Hoechst 33258 (1 mg/ $\mathrm{ml}$ ) for $20 \mathrm{~min}$. The fixed cells were incubated in blocking buffer [PBS containing 10\% fetal calf serum (FCS) and $0.2 \%$ Triton X-100] for $30 \mathrm{~min}$ and then for additional $30 \mathrm{~min}$ in PBS, 2\% bovine serum albumin (BSA), and anti-cytochrome c antibody (1:1000, clone 6H2.B4; PharMingen) and antiapoptosis-inducing factor $(1: 1000, \mathrm{CST})$. Cells were then washed 3 times in blocking buffer and incubated for $30 \mathrm{~min}$ in PBS containing $2 \% \mathrm{BSA}$, and $1 \mathrm{mg} / \mathrm{ml}$ of tetramethyl- rhodamine isothiocyanate-conjugated anti-mouse antibody (Invitrogen). Cells were then rinsed three times in blocking buffer, and coverslips were mounted onto slides. Morphological changes such as cell shrinkage, rounding and membrane blebbing were evaluated by microscopic inspection of cells.

In vitro cross-linking for detection of Bax oligomers. In vitro cross-linking for detection of Bax oligomers was performed according to the methods of Ling et al (26). In brief, cells ( $2 \times 10^{6}$ cells) were incubated in $1.0 \mathrm{ml}$ of cross-linking buffer (210 mM mannitol, $70 \mathrm{mM}$ sucrose, $1 \mathrm{mM}$ EGTA, $5 \mathrm{mM}$ HEPES, pH 7.4 and $0.05 \%$ digitonin) containing $1 \mathrm{mM} \mathrm{BMH}$ (Pierce Chemical) at room temperature for $60 \mathrm{~min}$. After incubation, cells were pelleted by centrifugation at $15,000 \mathrm{x} \mathrm{g}$ for $15 \mathrm{~min}$ at $4^{\circ} \mathrm{C}$ and suspended in buffer containing $62.5 \mathrm{mM}$ Tris- $\mathrm{HCl}, \mathrm{pH} 6.8,10 \%$ glycerol and 2\% SDS. The Bax oligomers were detected by immunoblot using anti-Bax antibody.

Cellular fractionation. For assay of release of cytochrome c and Smac/DIABLO, cells were fractionated into cytosolic and mitochondrial fractions as described previously (26). In brief, cells were washed with PBS and incubated in buffer containing $20 \mathrm{mM}$ HEPES-KOH, pH 7.2, $10 \mathrm{mM} \mathrm{KCl}$, $1.5 \mathrm{mM} \mathrm{MgCl} 2,1 \mathrm{mM}$ EDTA, $0.1 \mathrm{mM}$ phenylmethylsulfonyl fluoride, $10 \mu \mathrm{g} / \mathrm{ml}$ leupeptin and $10 \mu \mathrm{g} / \mathrm{ml}$ aprotinin at $4^{\circ} \mathrm{C}$ for $10 \mathrm{~min}$, and then cells were homogenized with a Dounce homogenizer for 50 strokes. The homogenates were centrifuged at $1000 \mathrm{x} \mathrm{g}$ for $10 \mathrm{~min}$ at $4^{\circ} \mathrm{C}$ to remove nuclear and membrane fractions. The supernatants were further centrifuged at $15,000 \mathrm{x} \mathrm{g}$ for $30 \mathrm{~min}$ at $4^{\circ} \mathrm{C}$, and collected as the cytosolic fraction. The pellet was further dissolved with lysis buffer containing $1 \%$ SDS as the mitochondrial fraction.

Analysis of combinatorial effects. Unless otherwise stated, data are expressed as mean \pm S.D. The significance of differences between experimental conditions was determined using a two-tailed Student's t-test. MTS assays were used to determine inhibition of cell survival after a 72-h treatment of multiple cell lines with different ratios of NVP-AEW541 and dasatinib. $\mathrm{IC}_{50}$ concentrations and combination indices for the effects of NVP-AEW541 and dasatinib were calculated using a commercially available software program (Calcusyn; Biosoft, Ferguson, MO) (27).

\section{Results}

NVP-AEW541 inhibits receptor phosphorylation and growth in malignant human glioma cell lines. To verify the capacity of NVP-AEW541 to inhibit the IGF-IR tyrosine kinase activity in glioma cells, T98G and U87 cells were treated with different concentrations of NVP-AEW541, and for varying durations. Cells were lysed and equal amounts of protein were fractionated for Western blot analysis. As shown in Fig. 1A and B, the phosphorylation of IGF-1R was significantly inhibited by NVP-AEW541 treatment in a dose- and time-dependent manner. To determine whether NVP-AEW541 could have a direct antiproliferative effect on glioma cell growth, five established malignant human glioma cell lines were treated with different doses of inhibitor. Cells were 


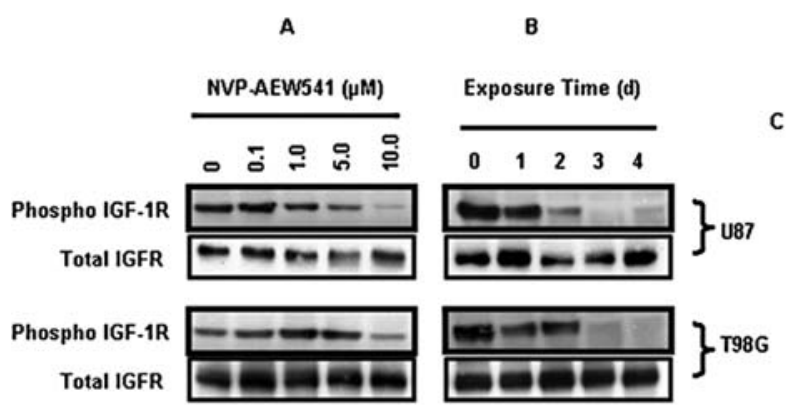

D
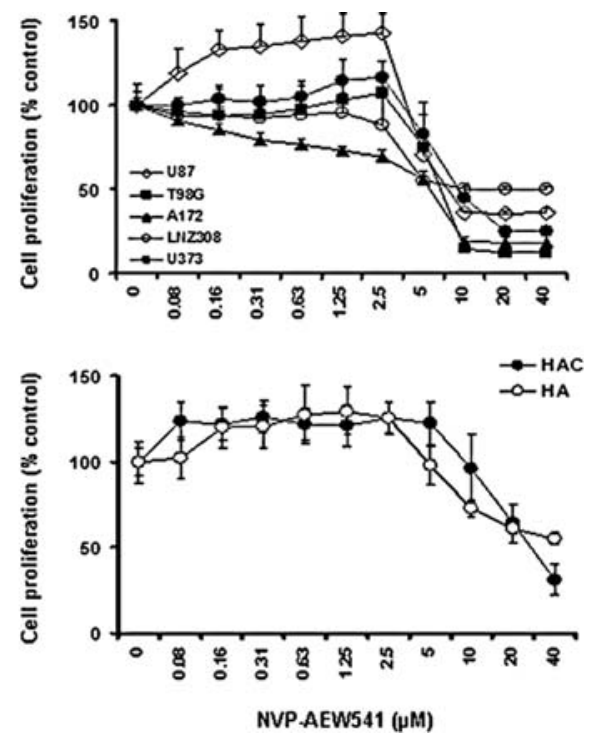

Figure 1. NVP-AEW541 inhibits receptor phosphorylation and induces growth inhibition in malignant human glioma cell lines. (A) U87 and T98G cells were seeded at $60 \%$ confluence and allowed to attach. Then, the cells were treated with varying concentrations of NVP-AEW541 for 1 day. Cell extracts were prepared, and equal amounts of protein (30 $\mu \mathrm{g} / \mathrm{lane})$ were separated by SDS-PAGE analysis and subjected to Western blot analysis with pIGF-1R antibody. The blots were subsequently stripped and reprobed with total IGF-1R antibody. (B) U87 and T98G cells were seeded at sub-confluence and allowed to attach overnight at $37^{\circ} \mathrm{C}$. Then, the cells were treated with $1 \mu \mathrm{M}$ of NVP-AEW541 for up to 4 days. Cell extracts were prepared, and equal amounts of protein ( 30 $\mu \mathrm{g} /$ lane) were separated by SDS-PAGE analysis and subjected to Western blot analysis with pIGF-1R antibody. The blots were subsequently stripped and reprobed with total IGF-1R antibody. (C and D) Logarithmically growing established human glioma cell lines (C) and normal human astrocytes (HA) and human cerebral astrocytes (HAC) (D) were incubated with varying concentrations of NVP-AEW541 for 3 days. The relationship between NVP-AEW541 concentration and cell numbers was assessed semiquantitatively by spectrophotometric measurement of MTS bioreduction. Points represent the mean of four measurements \pm S.D. There was a dose-dependent reduction in cell growth. Control cells $(0)$ were treated with equivalent concentrations of vehicle (DMSO).

cultured with increasing concentrations of NVP-AEW541 for 3 days and cell proliferation was assessed by MTS assay. Control cells were treated with equivalent concentrations of vehicle (DMSO) in the absence of NVP-AEW541. As shown in Fig. 1C, NVP-AEW541 treatment resulted in a dosedependent inhibition of cell proliferation with an $\mathrm{IC}_{50}$ ranging between 7.2 and $12.3 \mu \mathrm{M}$. At concentrations below $10 \mu \mathrm{M}$, there were no significant effects on the normal cells such as human astrocytes (HA) and human cerebellar astrocytes (HAC) (Fig. 1D). The therapeutic effect of NVP-AEW541 was further confirmed with a clonogenic assay (data not shown).

Effect of NVP-AEW541 on survival and cell cycle regulatory molecules. We then examined the effect of NVP-AEW541 on the phosphorylation of two major IGF-IR-related intracellular signaling pathways, specifically MAPK/ERK and PI3K (7). As shown in Fig. 2A (upper panel), the phosphorylation of Erk 1/2 and Akt was not inhibited by treatment with NVP-AEW541 at concentrations $\leq 10 \mu \mathrm{M}$ in T98G cells. Because recent studies in non-glioma cell lines showed that NVP-AEW541 caused G0/G1 cell cycle arrest, associated with down-regulation of cyclins D1, A, and E and pRB (7), we examined these targets in T98G cell line. Western blotting data showed that NVP-AEW541 resulted in only limited reduction in cyclin D1, cyclin D3, CDK4 and CDK6, at the highest tested concentration (Fig. 2A, lower panel). To examine the effect of NVP-AEW541 on cell viability, T98G, U87 and U373 human glioma cell lines were exposed to varying concentrations of inhibitor, or DMSO (control) and cell viability was assessed by trypan blue exclusion assay. As shown in Fig. 2B, there was a dose-dependent decrease in cell viability in response to treatment with NVP-AEW541. To address whether apoptotic signaling was induced by NVP-AEW541, T98G cells were treated with varying concentrations of NVP-AEW541 for $48 \mathrm{~h}$ and cleavage of caspases-8, $-9,-3$, and PARP was analyzed by Western blotting using antibodies that recognize both procaspase and cleaved fragments. NVP-AEW541 did not provoke caspase-8, -9 and -3 and PARP cleavage with generation of truncated fragments after $48 \mathrm{~h}$ of treatment (Fig. 2C).

Dasatinib inhibits glioma cell proliferation and increases NVP-AEW541-induced apoptosis. Because it has also been shown that NVP-AEW541 can inhibit other kinases, particularly insulin receptor, at concentrations above $2 \mu \mathrm{M}$ (13), we could not exclude the possibility that growth inhibition we observed at higher concentrations might be due to non-IGFRspecific effects. In addition, the observation of toxicity in normal astrocytes at concentrations above $10 \mu \mathrm{M}$ prompted us to examine whether the efficacy of lower $(1 \mu \mathrm{M})$ concentrations of NVP-AEW541 could be potentiated by combination with inhibition of other receptor tyrosine kinases involved in glioma proliferation. Because dasatinib can potentially block several such targets $(20,28)$, we hypothesized that this agent could effectively increase the activity of NVP-AEW541.

We first defined the concentration-response profile for dasatinib in malignant human glioma, examining the effect of this drug on growth of 3 established glioma cell lines and normal human cerebral astrocytes. Cells were cultured with increasing concentrations of dasatinib for 3 days and cell proliferation was assessed by MTS assay (Fig. 3A). We then 
A

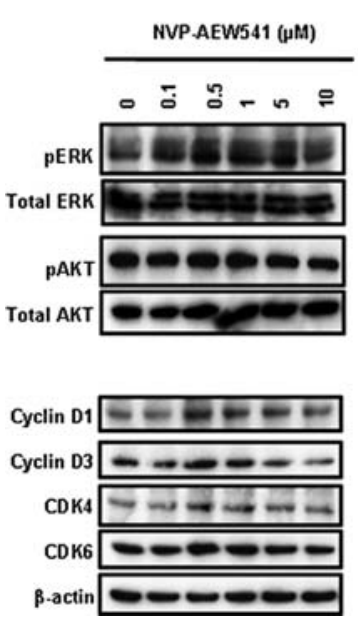

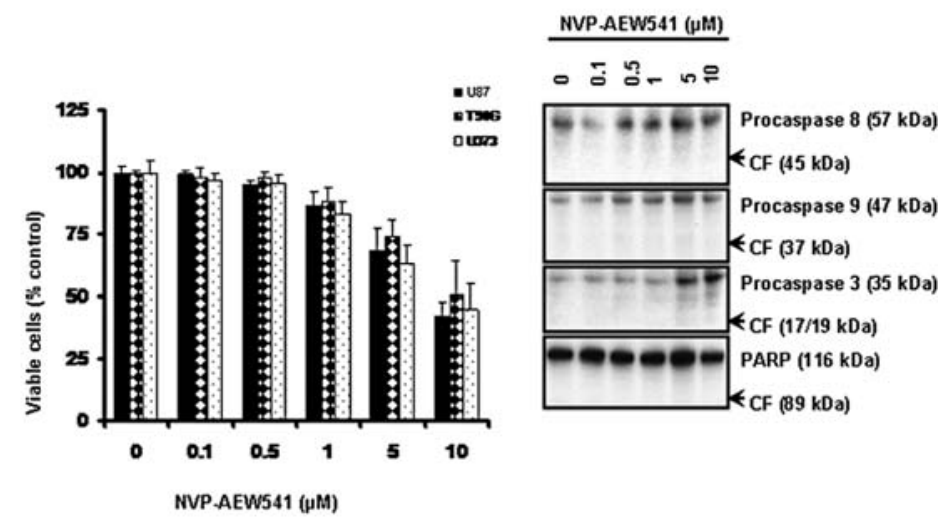

Figure 2. Effect of NVP-AEW541 on survival and cell cycle regulatory molecules. (A) T98G cells were seeded at sub-confluence and incubated overnight at $37^{\circ} \mathrm{C}$. Then, the cells were treated for $48 \mathrm{~h}$ with $0-10 \mu \mathrm{M}$ NVP-AEW541 for $48 \mathrm{~h}$. Cell extracts were prepared, and equal amounts of protein were separated and subjected to Western blot analysis with indicated antibodies. (B) Three established human glioma cell lines (U87, T98G and U373) were exposed for 2 days to varying concentrations of NVP-AEW541. Control cells (0) were treated with equivalent concentrations of vehicle (dimethyl sulfoxide, DMSO). At the end of the incubation period, the viable cell numbers were determined by trypan-blue exclusion assay. For each analysis, at least 400 cells were evaluated. The values represent the mean \pm standard deviation for two separate experiments performed in triplicate. (C) T98G cells were seeded at sub-confluence and incubated overnight at $37^{\circ} \mathrm{C}$. Then, the cells were treated with 0-10 $\mu \mathrm{M}$ NVP-AEW541 for $48 \mathrm{~h}$. Cell extracts were prepared, and equal amounts of protein were separated and subjected to Western blot analysis with indicated antibodies (CF, cleaved fragment).

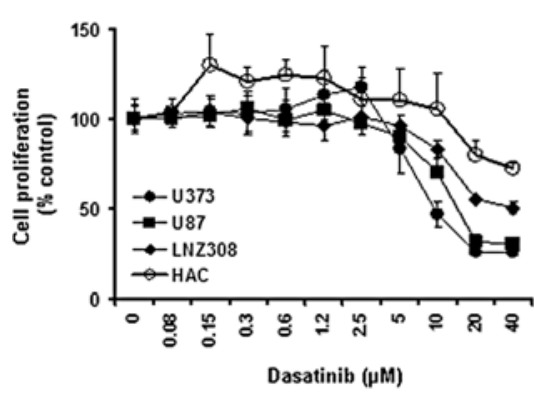

$\mathrm{Cl}=\mathbf{0 . 5 9 9}$
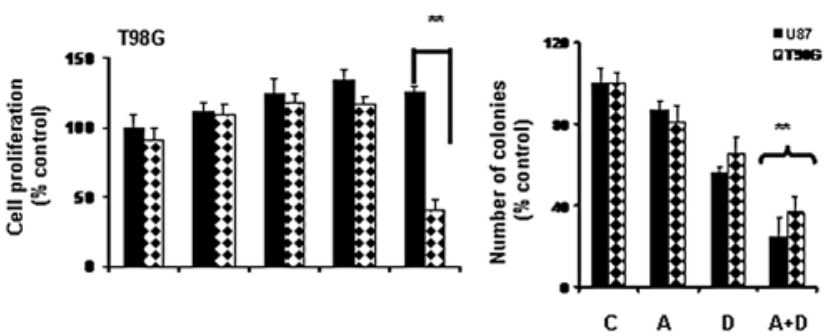

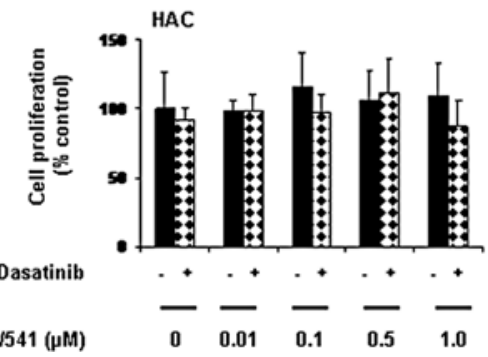

Figure 3. Dasatinib potentiates the action of NVP-AEW541 in glioma cells but not in non-neoplastic cell line. (A) Logarithmically growing established human glioma cell lines (U373, U87 and LNZ308) and human cerebral astrocytes (HAC) were incubated with varying concentrations of dasatinib for 3 days. The relationship between dasatinib concentration and cell numbers was assessed semiquantitatively by spectrophotometric measurement of MTS bioreduction. Points represent the mean of four measurements \pm S.D. There was a dose-dependent reduction in cell growth. Control cells $(0)$ were treated with equivalent concentrations of vehicle (DMSO). (B) Glioma (T98G) or normal cells (human cerebral astrocytes, HAC) were treated with NVP-AEW541 (0-1.0 $\mu$ M) with or without dasatinib $(3 \mu \mathrm{M})$, and after $72 \mathrm{~h}$ MTS assays were performed as described in Materials and methods. (C) Graph showing the relationship between colony counts ( \pm standard deviation) and concentration of inhibitors. Human glioma cell lines U87 and T98G were exposed to NVP-AEW541 ( $1 \mu$ M) with or without dasatinib $(3 \mu \mathrm{M})$ for $24 \mathrm{~h}$. On the following day, the media was changed and complete media was added. Cells were grown for an additional $10-14$ days in the absence of inhibitors. Control (C) cells were treated with equivalent concentrations of vehicle (DMSO). The values represent the mean \pm standard deviation for two separate experiments performed in triplicate $\left({ }^{* *} \mathrm{p}<0.005\right.$ versus control).

selected a low concentration $(3 \mu \mathrm{M})$, which had limited independent effects on glioma cell proliferation and no effect on non-neoplastic astrocytes (Fig. 3A) for combination with NVP-AEW541. To test the potential for therapeutic 
A

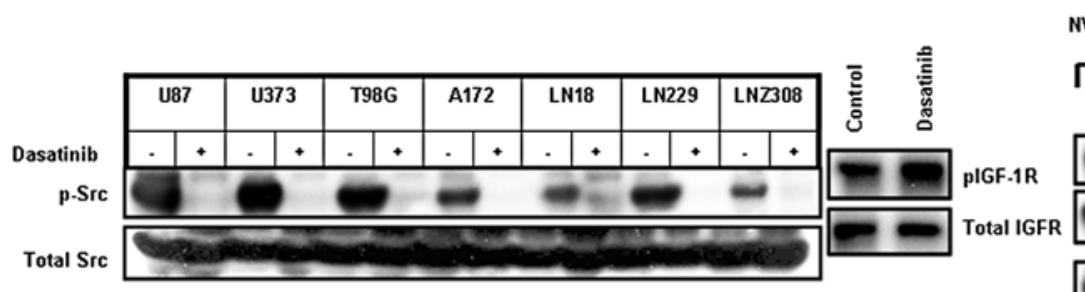

D
NVP.AEW541 ( $\mu M)$
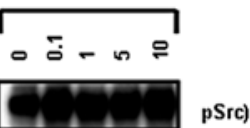

Total Src

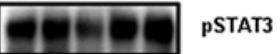

PSTAT3

Total STAT3

E

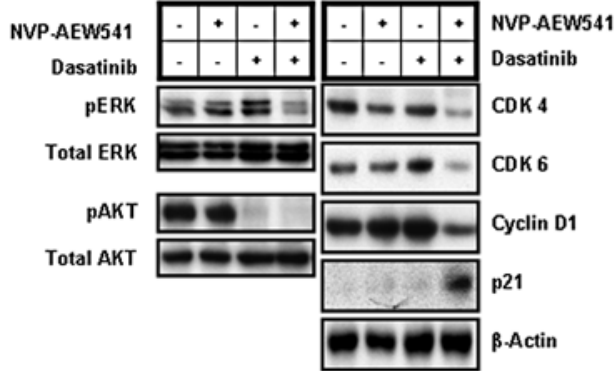

Figure. 4. The combination of dasatinib and NVP-AEW541 potentiates effects on signaling inhibition and cell cycle blockade. (A) Seven human glioma cell lines were incubated with $250 \mathrm{nM}$ dasatinib for $24 \mathrm{~h}$ and analyzed by Western blotting for activated Src (pSrc-Y416). The blot was subsequently stripped and reprobed with antibody directed against total Src. (B) T98G cells were incubated with dasatinib (3 $\mu \mathrm{M})$ for $24 \mathrm{~h}$ and proteins were separated and Western analysis was performed using phosphorylated IGF-1R antibody. The blot was subsequently stripped and reprobed with antibody directed against total IGFR. (C) T98G cells were treated with varying concentrations of NVP-AEW541 for $24 \mathrm{~h}$. Cell extracts were prepared, and equal amounts of protein (30 $\mu$ g/lane) were separated by SDS-PAGE analysis and subjected to Western blotting analysis with pSrc (Y416) or phospho-STAT3 (Y705) antibodies. The blots were subsequently stripped and reprobed with total Src or STAT3 antibodies. (D) T98G cells were seeded at $60 \%$ confluence and allowed to attach. Then, the cells were serum-starved $24 \mathrm{~h}$ and pretreated with $1 \mu \mathrm{M} \mathrm{NVP}-\mathrm{AEW} 541$, dasatinib $(3 \mu \mathrm{M})$ or the combination of both for $2 \mathrm{~h}$ and then left untreated or treated with $50 \mathrm{ng} / \mathrm{ml} \mathrm{EGF}$ or PDGF for $30 \mathrm{~min}$. Cell extracts were prepared, and equal amounts of protein $(30 \mu \mathrm{g} / \mathrm{lane})$ were separated by SDS-PAGE analysis and subjected to Western blot analysis with the indicated primary antibodies. The blots were subsequently stripped and reprobed against total receptor antibodies. (E, left) Logarithmically growing T98G cells were incubated for 2 days in the presence of NVP-AEW541 ( $1 \mu \mathrm{M})$ with or without dasatinib $(3 \mu \mathrm{M})$. The cells were lysed, and proteins were separated by SDS-PAGE and probed with specific antibodies which recognize pERK 1/2 and pAkt (Ser 473) as described in Materials and methods. The blots were subsequently stripped and reprobed against total Erk and Akt antibodies. (E, right) T98G cells were incubated for 2 days in the presence of NVP-AEW541 $(1 \mu \mathrm{M})$ with or without dasatinib $(3 \mu \mathrm{M})$. The cells were lysed, and equal amount of proteins were separated by SDSPAGE and probed with indicated antibodies. The blots were subsequently stripped and reprobed against $\beta$-actin.

potentiation, T98G cells were treated with several combinations of NVP-AEW541 $(0-1 \mu \mathrm{M})$ and dasatinib $(3 \mu \mathrm{M})$ followed by analysis of the data for synergistic interactions (Calcusyn, Biosoft). As shown in Fig. 3B (upper panel), the combination of NVP-AEW541 and dasatinib was found to synergistically increase the antiproliferative effect (combination index, CI: 0.599). In order to confirm the specificity of the inhibitors toward tumor cells, we compared the effect of NVP-AEW541 and dasatinib alone or in combination on normal cells (human cerebellar astrocytes, HAC). Exposure to $3 \mu \mathrm{M}$ dasatinib and $1 \mu \mathrm{M}$ NVP-AEW541 alone or in combination had little or no effect on these cells (Fig. 3B, lower panel). These results indicate that combination of NVP-AEW541 and dasatinib works selectively against tumor cells compared with non-neoplastic human astrocytes.

To characterize potential interactions between NVPAEW541 and dasatinib on cell viability, human glioma cell lines were exposed to $1 \mu \mathrm{M}$ of NVP-AEW541, $3 \mu \mathrm{M}$ dasatinib, or the combination of both and cell viability was assessed by clonogenic growth assay. Clonogenic growth assays (Fig. 3C) clearly demonstrate that the combination of both inhibitors was substantially more effective than either single agent and showed a significant decrease on cell survival.
The combination of dasatinib and NVP-AEW541 potentiates effects on signaling inhibition and cell cycle blockade. The effects of dasatinib on cell signaling were evaluated in seven established glioma cell lines. The baseline levels of Src and activated Src (pY416-Src) were measured by Western blotting. Dasatinib caused complete inhibition of Src activity, as measured by phosphorylation at Y416 after treatment for $24 \mathrm{~h}$ (Fig. 4A). We found that Src activity was completely inhibited in all cell lines, but total Src levels were not affected. Because IGF system can also be activated by other oncoproteins such as p60src (29), we examined the effect of dasatinib on IGF-1R phosphorylation in T98G cells. Dasatinib treatment has no effect on the levels of IGF-1R phosphorylation (Fig. 4B). Then to examine the effects of NVPAEW541 on Src and STAT3, T98G cells were treated with either vehicle or varying concentrations of NVP-AEW541, and the cell lysates were processed for Western blotting as described in Materials and methods. As shown in Fig. 4C, NVP-AEW541 had no effect on the levels of phosphorylation of c-Src and STAT3. To address effect of NVP-AEW541 and dasatinib or the combination of both on EGFR and PDGFR phosphorylation, T98G cells were pretreated with or without NVP-AEW541 or dasatinib or the combination of both for $2 \mathrm{~h}$ followed by $30 \mathrm{~min}$ of EGF or PDGF stimulation. 
A
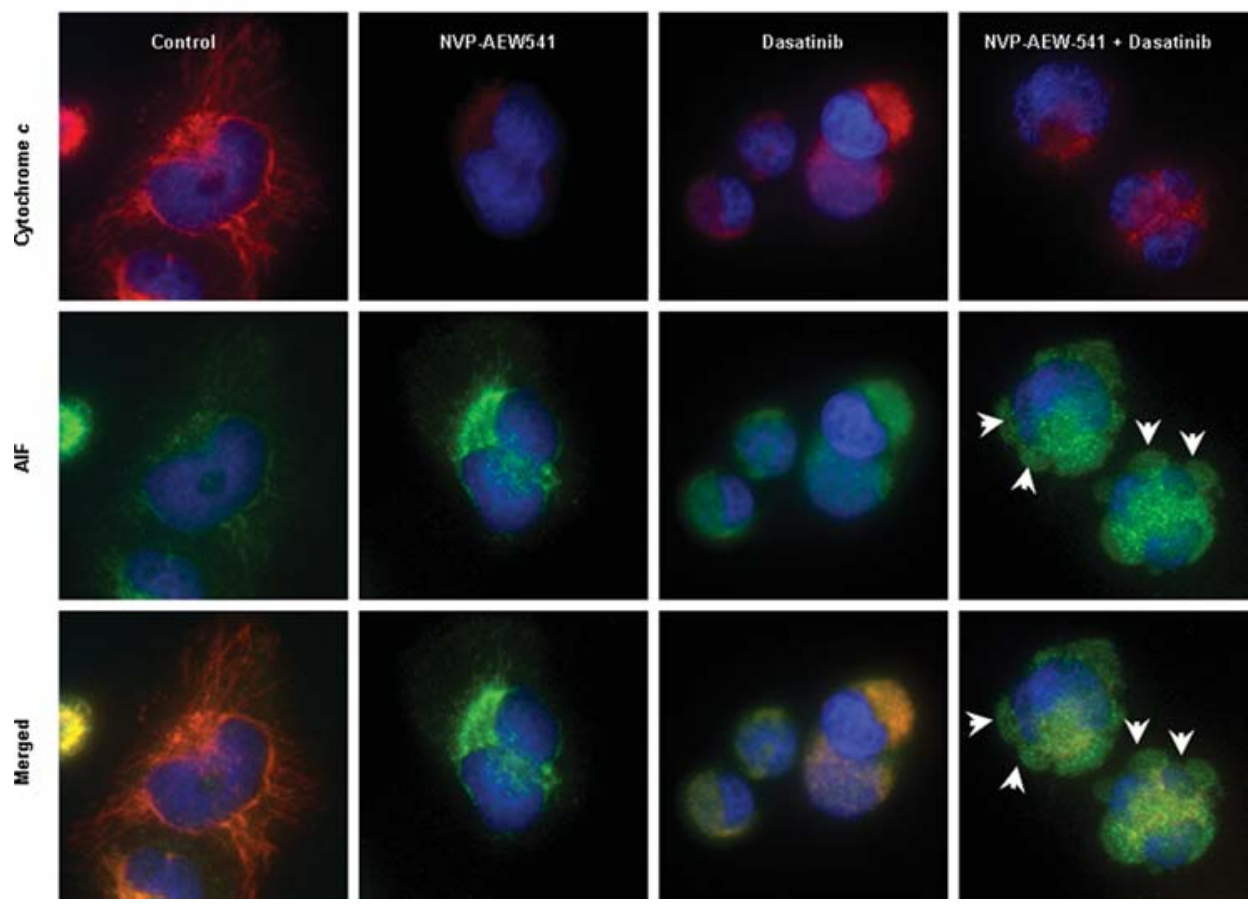

C

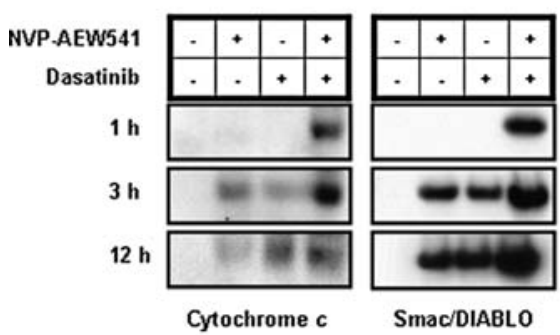

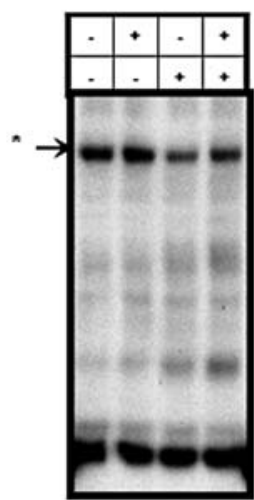

U87

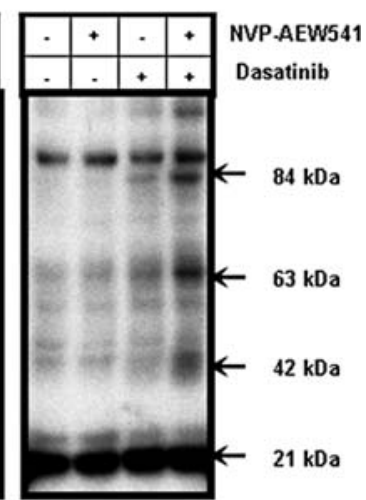

T98G

Figure 5. (A) Dasatinib enhances NVP-AEW541-induced mitochondrial dysfunction. (A) Logarithmically growing T98G cells were incubated with $1.0 \mu \mathrm{M}$ NVP-AEW541 (A), 3.0 $\mu \mathrm{M}$ dasatinib (D) or the combination of both (A and D) for $6 \mathrm{~h}$. Cells were fixed, permeabilized and stained with antibodies specific for cytochrome $\mathrm{c}$ and AIF as described under Materials and methods. The cells were counterstained with Hoechst 33342 to visualize nuclei. Immunofluorescence detection of AIF and cytochrome c normally yields a punctate cytoplasmic staining (control). Cells exposed to NVP-AEW541 or dasatinib for 6 h resulted in diffuse staining for cytochrome $\mathrm{c}$ and nuclear translocation of AIF in the majority of the cells. The combination of both NVP-AEW541 and dasatinib resulted in an increased diffuse staining of cytochrome $\mathrm{c}$ in the cytoplasm and translocation of AIF from the mitochondria into the nucleus and membrane blebbing (arrow head). This experiment was repeated three times, yielding comparable results. (B) T98G cells were incubated in the presence of $3 \mu \mathrm{M}$ dasatinib with or without NVP-AEW541 $(1 \mu \mathrm{M})$ for the indicated durations. Cytosolic fraction was prepared as described in the Materials and methods. Equal amounts of protein (30 $\mu \mathrm{g}$ of total protein/lane) were separated by SDS-PAGE and subjected to immunoblot analysis with the indicated antibodies. (C) Logarithmically growing U87 and T98G cells were incubated for $24 \mathrm{~h}$ in the presence of NVP-AEW541 (1 $\mu \mathrm{M})$ with or without dasatinib $(3 \mu \mathrm{M})$. After treatment, cells were harvested and incubated with protein cross-linker $\mathrm{BMH}$ at room temperature for $60 \mathrm{~min}$. After incubation, cells were lysed, and an equal amount of lysates $(30 \mu \mathrm{g}$ of protein) was subjected to a 4-12\% SDS-PAGE. After transferring to a membrane, the oligomers of Bax were detected by Western blot analysis as described in Materials and methods. The non-specific $\left(^{*}\right)$ band $(\sim 95 \mathrm{kDa})$ served as the sample loading control.

Cell lysates were prepared and probed with antibodies recognizing phosphorylated EGFR (Y845) or PDGFR- $\beta$ (Y751) by Western blot analysis. EGF-induced receptor phosphorylation was significantly reduced by both dasatinib (Fig. 4D, lane 2 versus 3) and NVP-AEW541 (Fig. 4D, lane 2 versus 4). Both dasatinib and NVP-AEW541 also significantly reduced PDGF-induced receptor activation (Fig. 4D, lane 6 versus lanes 7 through 9).
To determine whether the combination of NVP-AEW541 and dasatinib potentiated effects on other downstream signaling mediators, we examined several key cell cycle regulatory proteins in response to these agents, alone and in combination. As shown in Fig. 4E, the phosphorylation of Erk $1 / 2$ was minimally inhibited by NVP-AEW541 treatment in T98G cells, whereas dasatinib produced a modest degree of inhibition. Combined exposure to NVP-AEW541 and 
dasatinib resulted in significant reduction of ERK activation by $48 \mathrm{~h}$ (Fig. 4E). Although dasatinib alone reduced Akt phosphorylation, NVP-AEW541 did not, but the combination of both led to further reduction in pAkt levels. In contrast, total ERK and Akt levels remained unchanged with any treatment at $48 \mathrm{~h}$.

We then tested the effects of NVP-AEW541 and dasatinib combinations on various cell cycle regulatory proteins. T98G cells were treated with $1 \mu \mathrm{M}$ NVP-AEW541, dasatinib (3 $\mu \mathrm{M})$ or a combination of both for $48 \mathrm{~h}$, and Western analysis was performed. The combination led to significant reduction in CDK4, CDK6 and cyclin D1, in association with upregulation of p21 (Fig. 4E, right).

Release of cytochrome C, AIF and Bax oligomerization is closely associated with apoptosis induced by NVP-AEW541 and dasatinib treatment. It has been proposed that caspases and mitochondria can engage in a self-amplification loop in which the release of mitochondrial apoptogenic proteins activates caspases that would in turn increase the mitochondrial membrane permeability (30). Additional episodes of cytochrome c release may occur, which have been shown to be due to caspase-3-dependent cleavage of Bcl-2 (31) and Bax activation (32). To determine if the combination of NVPAEW541 and dasatinib was promoting mitochondrially mediated apoptotic signaling, we examined the localization of cytochrome c and AIF after NVP-AEW541 and dasatinib treatment, alone or in combination, employing both indirect immunofluorescence microscopy and immunoblot analysis. Immunofluorescence detection of AIF and cytochrome c in untreated control cells showed a punctate cytoplasmic staining pattern with some preference for the perinuclear area (Fig. 5A). In contrast, cells incubated with NVP-AEW541 and dasatinib showed an increased diffuse staining of cytochrome $\mathrm{c}$ in the cytoplasm and translocation of AIF from the mitochondria into the nucleus and membrane blebbing as early as $6 \mathrm{~h}$ (Fig. 5A). To determine whether the observed cytochrome $\mathrm{c}$ release is indeed the trigger of cell death, we evaluated the effect of dasatinib and NVP-AEW541 on Smac/ DIABLO release to the cytoplasm by immunoblot analysis after cell fractionation. As shown in Fig. 5B, the signal of cytochrome $\mathrm{c}$ and Smac/DIABLO was undetectable in untreated control cells, and significantly more apparent in cells treated with both inhibitors than either alone at all time points surveyed.

Studies from numerous laboratories have shown that mitochondrial membrane potential is tightly regulated by pro- and anti-apoptotic proteins of the Bcl-2 family (33). In particular, loss of mitochondrial membrane potential is widely accepted to require the activation of a multidomain protein, notably Bak or Bax. The presence and activation of either Bak or Bax is thought to be sufficient to induce loss of mitochondrial membrane potential. Previous reports have demonstrated that Bax translocation to the mitochondria and alteration in protein conformation (34) are necessary steps in cells undergoing apoptosis (35). To address the potential contribution of Bax alterations to the combinatorial effects of NVP-AEW541 and dasatinib, T98G and U87 cells were exposed to both agents, alone or in combination, for $24 \mathrm{~h}$. After exposure, cells were treated with the membrane-permeable protein cross-linker $\mathrm{BMH}$, and then the oligomers of Bax were detected by Western blot analysis. As shown in Fig. 5C, NVP-AEW541 and dasatinib induces the formation of Bax homodimers (42 kDa), homotrimers $(63 \mathrm{kDa})$ and homotetramers $(84 \mathrm{kDa})$ with three bands of slower mobility than that of their monomer $(21 \mathrm{kDa})$. For example, the signals of Bax oligomers were barely detectable in untreated control cells, but clearly detectable in cells after exposure to NVPAEW541 or dasatinib. Cotreatment of cells with these inhibitors consistently caused a significant increase in Bax oligomerization (Fig. 5C). In summary, these findings suggest that the release of cytochrome c, AIF and oligomerization of Bax may play an important role in the regulation of NVPAEW541 and dasatinib-induced apoptosis (Fig. 5A-C).

Effect of overexpression of Bcl-2 and Akt on NVP-AEW541 and dasatinib-induced apoptosis. In light of the recent reports that attributed IGF-1R receptor inhibitor induced apoptosis to Bax activation (2), we investigated the effects of NVP-AEW541 and dasatinib treatment on Akt, Bcl-2 and Bax expression level. T98G cells were treated with $1 \mu \mathrm{M}$ NVP-AEW541 alone or in combination with 1 or $3 \mu \mathrm{M}$ dasatinib for $48 \mathrm{~h}$, and Western analysis was performed. Upon treatment of the cells with $1 \mu \mathrm{M}$ NVP-AEW541, a modest decrease in the phosphorylation of Akt and Bcl-2 was observed. Incubation of the cells with $1 \mu \mathrm{M}$ dasatinib alone significantly diminished Akt phosphorylation and the phosphorylation of Akt was completely abolished in the cells treated with the combinations of NVP-AEW541 and dasatinib (Fig. 6A, upper panel), whereas there was a significant decrease in Bcl-2 (Fig. 6A, middle panel), as estimated by densitometry. Bax has been shown to undergo posttranslational modification during apoptosis. For example, p18 Bax generation through wild-type Bax cleavage has been observed in response to various chemotherapeutic agents (36). Treatment with NVP-AEW541 or dasatinib alone had modest effects on the levels of cleaved Bax (Fig. 6A, lower panel). In contrast, combined treatment with both agents resulted in a significant increase in the cleaved forms of Bax.

Pursuant to the above finding, and to explore the mechanism responsible for the pronounced enhancement of apoptosis induction, we assessed the effect of enforced Bcl-2 and Akt overexpression on T98G cells. It has been well established that Akt and Bcl-2 represents a key signaling component in cell survival and apoptotic pathway $(37,38)$. T98G cells were transiently transfected with Bcl-2, Myr-Akt, and empty vector cDNA and protein expression was verified by Western analysis (data not shown). Cells were treated with NVP-AEW541 $(1 \mu \mathrm{M})$ and dasatinib $(3 \mu \mathrm{M})$ for $24 \mathrm{~h}$. Immunoblot analysis and cell viability assay revealed that transient transfection of Bcl-2 and Myr-Akt led to a significant reduction of NVP-AEW541 and dasatinib-induced caspase-3 and PARP activation (Fig. 6B, upper panel) and cell death (Fig. 6B, lower panel); i.e., 21 and 12\% of cells were apoptotic in Bcl-2- and Myr-Akt-transfected cells compared to $37 \%$ in vector backbone-transfected cells after 24 h treatment with NVP-AEW541 and dasatinib.

Then we explored whether Bcl-2 and Myr-Akt play any role on oligomerizations of Bax in NVP-AEW541 and dasatinib-induced apoptosis. To address this issue, T98G 
A

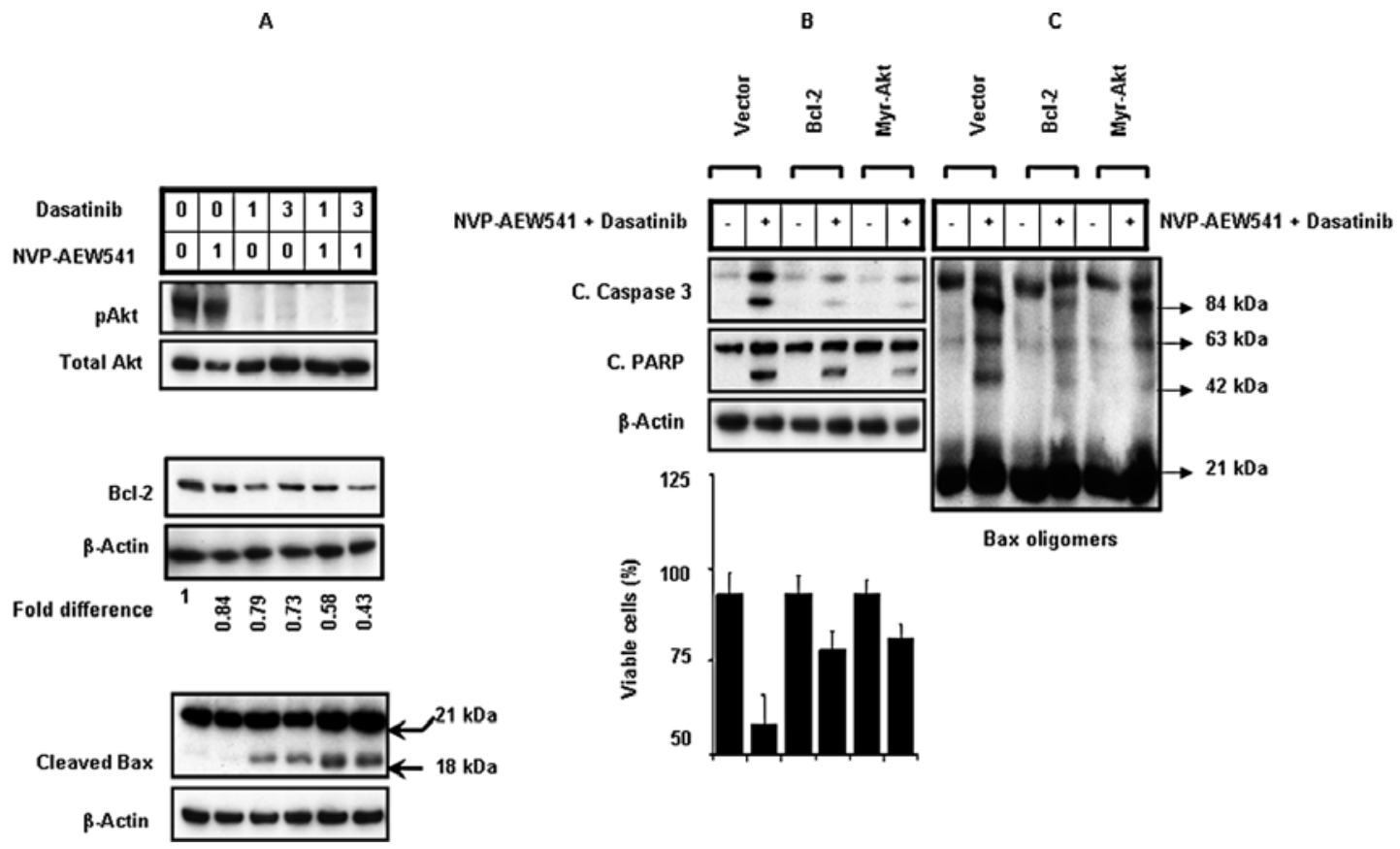

Figure 6. Effects of Bcl-2 and Akt on NVP-AEW541 and dasatinib-induced apoptosis and Bax oligomerization. (A) Logarithmically growing T98G cells were treated with NVP-AEW541 $(1 \mu \mathrm{M})$ with or without dasatinib $(1$ or $3 \mu \mathrm{M})$ for $48 \mathrm{~h}$. Control cells received equal amounts of DMSO. Cell extracts were prepared, and equal amounts of protein $(30 \mu \mathrm{g} /$ lane) were separated by SDS-PAGE analysis and subjected to Western blotting analysis with the indicated primary antibodies. The blots were subsequently stripped and reprobed against total Akt or B-actin. (B) T98G cells were seeded at $60 \%$ confluence and allowed to attach overnight. Cells were transiently transfected with empty vector, Bcl-2 or Myr-Akt cDNA as described in the Materials and methods. After $36 \mathrm{~h}$ transfection, cells were treated with NVP-AEW541 $(1.0 \mu \mathrm{M})$ and dasatinib $(3.0 \mu \mathrm{M})$, alone or in combination, or with same volume of DMSO for $24 \mathrm{~h}$. Cells were harvested and equal amounts of protein $(30 \mu \mathrm{g} / \mathrm{lane})$ were separated by SDS-PAGE analysis and subjected to Western blot analysis with the indicated primary antibodies. The blots were subsequently stripped and reprobed against $\beta$-actin. In parallel, cell viability was determined by trypan blue exclusion analysis. For each analysis, at least 400 cells were evaluated in duplicate. The values represent the mean \pm standard deviation for two separate experiments performed in triplicate $\left({ }^{* *} \mathrm{p}<0.005\right)$. (C) T98G cells were seeded at $60 \%$ confluence and allowed to attach overnight. Cells were transiently transfected with empty vector, Bcl-2 or Myr-Akt cDNA as described in the Materials and methods. After $36 \mathrm{~h}$ transfection, cells were treated with NVPAEW541 $(1.0 \mu \mathrm{M})$ and dasatinib $(3.0 \mu \mathrm{M})$ or with same volume of DMSO for $24 \mathrm{~h}$. After treatment, cells were harvested and incubated with protein crosslinker $\mathrm{BMH}$ at room temperature for $60 \mathrm{~min}$. After incubation, cells were lysed, and an equal amount of lysates (30 $\mu \mathrm{g}$ of protein) were subjected to a $4-12 \%$ SDS-PAGE. After membrane transfer, Bax oligomerization was detected by Western blot analysis as described in Materials and methods.

cells were transiently transfected and exposed to NVPAEW541 $(1 \mu \mathrm{M})$ and dasatinib $(3 \mu \mathrm{M})$ for $24 \mathrm{~h}$. Control cells received equal concentrations of DMSO. After exposure, cells were treated with the membrane-permeable protein crosslinker $\mathrm{BMH}$, and then the oligomers of Bax were detected by Western blot analysis. As shown in Fig. 6C, the effect of the combination of NVP-AEW541 and dasatinib on the induced formation of Bax homodimers (42 kDa), homotrimers (63 kDa) and homotetramers $(84 \mathrm{kDa})$ was significantly reduced by transfection with Bcl-2 and Myr-Akt. Taken together, these data support the role of Akt inhibition and activation of proapoptotic Bcl family members in mediating the synergistic apoptotic response induced by the combination of NVPAEW541 and dasatinib.

\section{Discussion}

Insulin-like growth factor-IR inhibitors are a novel class of chemotherapeutic agents that have shown promise in initial preclinical studies (39-41), although their potential for activity in malignant gliomas, which are known to have activation of IGFR as well as a host of other tyrosine kinases, has remained uncertain. To address this issue, we evaluated the effects of IGF-IR kinase inhibition by NVP-AEW541 in a panel of malignant human glioma cell lines. The effect of NVPAEW541 on glioma cell lines was observed at an $\mathrm{IC}_{50}$ in the low micromolar range. The concentrations of NVPAEW541 found in this study to inhibit cell proliferation of the glioma cell lines were higher than those found to be effective against multiple myeloma (MM) (14), where $\mathrm{IC}_{50}$ values of 0.1-0.5 $\mu \mathrm{M}$ were noted. This could be due to cellular and subcellular pharmacology of NVP-AEW541 between different cell types, or differences between cancers in their degree of IGF-IR dependence. Glioma cells, in particular, are known to commonly have aberrant activation of EGFR and PDGFR, which may promote cell proliferation and survival in the setting of IGFR blockade.

Previous studies on the mechanism of action of NVPAEW541 indicate that this compound affects several elements involved in the control of cell cycle progression and apoptosis (7). NVP-AEW541 caused a progressive accumulation of MM cells in G0/G1 phases with a marked decrease in the percentage of cells in S phase. In addition, NVP-AEW541 also decreased the levels of CCND1, CCNA, CCNE and pRb that regulate the cell cycle progression (42). Decrease of $\mathrm{pRb}$ and CCNE has also been shown to occur in MM cells treated with other IGF-IR kinase inhibitors, such as Ciclolignan PPP (43) or NVP-ADW742 (14). Although we noted that concen- 
trations of NVP-AEW541 were able to induce apoptosis in addition to antiproliferative effects in glioma cell lines, these concentrations also had some inhibitory activity on nonneoplastic astrocytes, suggesting the potential involvement of additional molecular targets, such as the insulin receptor (13).

We therefore questioned whether the efficacy of IGF-IR inhibition by NVP-AEW541 could be enhanced by combination with inhibition of other tyrosine kinase receptors involved in glioma growth and apoptosis resistance. Previous studies in other tumor types have demonstrated that NVPAEW541 produces synergistic growth inhibition when combined with other agents $(44,45)$, which may reflect the presence of significant cross-talk and compensatory growth stimulatory effects between IGF-IR and other tyrosine kinase receptors, particularly EGFR family members (46-48). We hypothesized that combining NVP-AEW541 with a different class of kinase inhibitor that blocked EGFR among other targets would have enhanced efficacy in inhibiting glioma cell proliferation and survival. In this regard, dasatinib (BMS354825 ) is an orally bioavailable tyrosine kinase inhibitor, which shows exceptionally promiscuous inhibitory activity against multiple receptor targets, other than IGFR, that are relevant in glioma growth (49). As with NVP-AEW541, dasatinib monotherapy has predominantly proven to be cytostatic in preclinical (23) and early phase clinical trials for these tumors (50), supporting the rationale for exploring combination approaches with such agents.

Our results show that the exposure of glioma cells to low concentrations of NVP-AEW541 and dasatinib significantly enhanced proliferation inhibition and increased apoptotic cell death as verified by cell viability and clonogenic assays and morphological observations. At these concentrations, there were no significant effects on normal human astrocytes or human cerebellar astrocytes. Our studies demonstrated that combining NVP-AEW541 and dasatinib induced the disruption of mitochondrial function with the release of cytochrome $\mathrm{c}$ and Smac/DIABLO from mitochondria to the cytosol. The release of cytochrome $\mathrm{c}$ from mitochondria has been shown to play a crucial role in many apoptotic signaling cascades through the activation of the downstream effector caspases (51). To our knowledge, the observation of Bax oligomerization in NVP-AEW541 and dasatinib-induced apoptosis is new. Based on the ability of this protein to form channels in synthetic lipid membranes, several models have been proposed that would allow Bax to form a cytochrome c-conducting channel. Cross-linking experiments of Bax, followed by Western blot analysis, revealed the existence of several Baximmunoreactive bands, suggesting the presence of Bax oligomers (52), which promote this channel forming process.

These studies demonstrated that although NVP-AEW541 and dasatinib each independently inhibited cell proliferation, but had modest efficacy in inducing apoptosis, combined treatment with dasatinib led to synergistic inhibition of proliferation and induction of apoptosis. The latter was associated with enhanced cytochrome c release, activation of Bax and mitochondrial injury suggesting the involvement of the intrinsic cell death pathway. The activation of Bax, including Bax conformational changes and oligomerization, appears to play a crucial role in the initiation of NVP-AEW541 and dasatinib-induced apoptosis. This effect could be counteracted by overexpression of Bcl-2 or constitutively active Akt, suggesting the critical involvement of Akt and $\mathrm{Bcl}$ family signaling pathways in NVP-AEW541 and dasatinib-induced Bax activation and apoptosis. From a clinical standpoint, our data suggest that combining NVP-AEW541 and dasatinib may provide significantly improved therapeutic efficacy against malignant human glioma compared to the use of either agent alone. This fits with observations in lung cancer and glioblastoma, that resistance to anti-EGFR therapy may in part relate to up-regulation of other signaling targets, such as IGF-IR (5,53-55). Cotargeting IGF-IR and EGFR may provide a strategy for proactively addressing this potential resistance mechanism that may translate into an attractive therapeutic combination in the clinical setting.

\section{Acknowledgements}

This work was supported by NIH grant PO1NS40923. We thank Naomi Agostino for technical assistance.

\section{References}

1. Evan GI and Vousden KH: Proliferation, cell cycle and apoptosis in cancer. Nature 411: 342-348, 2001

2. Wilsbacher JL, Zhang Q, Tucker LA, et al: Insulin-like growth factor-1 receptor and ErbB kinase inhibitor combinations block proliferation and induce apoptosis through cyclin D1 reduction and Bax activation. J Biol Chem 283: 23721-23730, 2008.

3. Myers MG Jr, Grammer TC, Wang LM, et al: Insulin receptor substrate-1 mediates phosphatidylinositol 3'-kinase and p70S6k signaling during insulin, insulin-like growth factor-1, and interleukin-4 stimulation. J Biol Chem 269: 28783-28789, 1994.

4. Hofmann F and Garcia-Echeverria C: Blocking the insulin-like growth factor-I receptor as a strategy for targeting cancer. Drug Discov Today 10: 1041-1047, 2005.

5. Jones HE, Goddard L, Gee JM, et al: Insulin-like growth factorI receptor signalling and acquired resistance to gefitinib (ZD1839; Iressa) in human breast and prostate cancer cells. Endocr Relat Cancer 11: 793-814, 2004.

6. Morgillo F, Woo JK, Kim ES, Hong WK and Lee HY: Heterodimerization of insulin-like growth factor receptor/epidermal growth factor receptor and induction of survivin expression counteract the antitumor action of erlotinib. Cancer Res 66: 10100-10111, 2006.

7. Maiso P, Ocio EM, Garayoa M, et al: The insulin-like growth factor-I receptor inhibitor NVP-AEW541 provokes cell cycle arrest and apoptosis in multiple myeloma cells. Br J Haematol 141: 470-482, 2008.

8. Tanno B, Mancini C, Vitali R, et al: Down-regulation of insulin-like growth factor I receptor activity by NVP-AEW541 has an antitumor effect on neuroblastoma cells in vitro and in vivo. Clin Cancer Res 12: 6772-6780, 2006.

9. Lu D, Zhang H, Ludwig D, et al: Simultaneous blockade of both the epidermal growth factor receptor and the insulin-like growth factor receptor signaling pathways in cancer cells with a fully human recombinant bispecific antibody. J Biol Chem 279: 2856-2865, 2004

10. Goetsch L, Gonzalez A, Leger O, et al: A recombinant humanized anti-insulin-like growth factor receptor type I antibody (h7C10) enhances the antitumor activity of vinorelbine and anti-epidermal growth factor receptor therapy against human cancer xenografts. Int J Cancer 113: 316-328, 2005.

11. Camirand A, Zakikhani M, Young F and Pollak M: Inhibition of insulin-like growth factor-1 receptor signaling enhances growthinhibitory and proapoptotic effects of gefitinib (Iressa) in human breast cancer cells. Breast Cancer Res 7: R570-579, 2005.

12. Desbois-Mouthon C, Cacheux W, Blivet-Van Eggelpoel MJ, et al: Impact of IGF-1R/EGFR cross-talks on hepatoma cell sensitivity to gefitinib. Int J Cancer 119: 2557-2566, 2006.

13. Garcia-Echeverria C, Pearson MA, Marti A, et al: In vivo antitumor activity of NVP-AEW541-a novel, potent, and selective inhibitor of the IGF-IR kinase. Cancer Cell 5: 231-239, 2004. 
14. Mitsiades CS, Mitsiades NS, McMullan CJ, et al: Inhibition of the insulin-like growth factor receptor-1 tyrosine kinase activity as a therapeutic strategy for multiple myeloma, other hematologic malignancies, and solid tumors. Cancer Cell 5: 221-230, 2004.

15. Schlessinger J: New roles for Src kinases in control of cell survival and angiogenesis. Cell 100: 293-296, 2000.

16. Doggrell SA: BMS-354825: a novel drug with potential for the treatment of imatinib-resistant chronic myeloid leukaemia. Expert Opin Investig Drugs 14: 89-91, 2005.

17. Chang YM, Kung HJ and Evans CP: Nonreceptor tyrosine kinases in prostate cancer. Neoplasia 9: 90-100, 2007.

18. Nam S, Kim D, Cheng JQ, et al: Action of the Src family kinase inhibitor, dasatinib (BMS-354825), on human prostate cancer cells. Cancer Res 65: 9185-9189, 2005.

19. Shor AC, Keschman EA, Lee FY, et al: Dasatinib inhibits migration and invasion in diverse human sarcoma cell lines and induces apoptosis in bone sarcoma cells dependent on Src kinase for survival. Cancer Res 67: 2800-2808, 2007.

20. Song L, Morris M, Bagui T, Lee FY, Jove R and Haura EB: Dasatinib (BMS-354825) selectively induces apoptosis in lung cancer cells dependent on epidermal growth factor receptor signaling for survival. Cancer Res 66: 5542-5548, 2006.

21. Summy JM and Gallick GE: Src family kinases in tumor progression and metastasis. Cancer Metastasis Rev 22: 337-358, 2003.

22. Trevino JG, Summy JM, Lesslie DP, et al: Inhibition of Src expression and activity inhibits tumor progression and metastasis of human pancreatic adenocarcinoma cells in an orthotopic nude mouse model. Am J Pathol 168: 962-972, 2006.

23. Milano V, Piao Y, LaFortune T and de Groot J: Dasatinibinduced autophagy is enhanced in combination with temozolomide in glioma. Mol Cancer Ther 8: 394-406, 2009.

24. Riss TL and Moravec RA: Use of multiple assay endpoints to investigate the effects of incubation time, dose of toxin, and plating density in cell-based cytotoxicity assays. Assay Drug Dev Technol 2: 51-62, 2004.

25. Riss TL and Moravec RA: Comparison of MTT, XTT and a novel tetrazolium compound MTS for in vitro proliferation and chemosensitivity assays. Mol Biol Cell 3: 184, 1992.

26. Ling YH, Lin R and Perez-Soler R: Erlotinib induces mitochondrial-mediated apoptosis in human H3255 non-smallcell lung cancer cells with epidermal growth factor receptor L858R mutation through mitochondrial oxidative phosphorylation-dependent activation of Bax and Bak. Mol Pharmacol 74: 793-806, 2008

27. Chou TC and Talalay P: Quantitative analysis of dose-effect relationships: the combined effects of multiple drugs or enzyme inhibitors. Adv Enzyme Regul 22: 27-55, 1984.

28. Haluska P, Carboni JM, Loegering DA, et al: In vitro and in vivo antitumor effects of the dual insulin-like growth factor-I/insulin receptor inhibitor, BMS-554417. Cancer Res 66: 362-371, 2006.

29. Peterson JE, Kulik G, Jelinek T, Reuter CW, Shannon JA and Weber MJ: Src phosphorylates the insulin-like growth factor type I receptor on the autophosphorylation sites. Requirement for transformation by Src. J Biol Chem 271: 31562-31571, 1996.

30. Marzo I, Susin SA, Petit PX, et al: Caspases disrupt mitochondrial membrane barrier function. FEBS Lett 427: 198-202, 1998.

31. Chen Q, Gong B and Almasan A: Distinct stages of cytochrome c release from mitochondria: Evidence for a feedback amplification loop linking caspase activation to mitochondrial dysfunction in genotoxic stress induced apoptosis. Cell Death Differ 7: 227-233, 2000 .

32. Finucane DM, Bossy-Wetzel E, Waterhouse NJ, Cotter TG and Green DR: Bax-induced caspase activation and apoptosis via cytochrome $\mathrm{c}$ release from mitochondria is inhibitable by Bcl-xL. J Biol Chem 274: 2225-2233, 1999.

33. Youle RJ and Strasser A: The Bcl-2 protein family: opposing activities that mediate cell death. Nat Rev Mol Cell Biol 9: 47-59, 2008.

34. Antignani A and Youle RJ: How do Bax and Bak lead to permeabilization of the outer mitochondrial membrane? Curr Opin Cell Biol 18: 685-689, 2006.
35. Stankiewicz AR, Lachapelle G, Foo CP, Radicioni SM and Mosser DD: Hsp70 inhibits heat-induced apoptosis upstream of mitochondria by preventing Bax translocation. J Biol Chem 280: 38729-38739, 2005.

36. Wood DE, Thomas A, Devi LA, et al: Bax cleavage is mediated by calpain during drug-induced apoptosis. Oncogene 17: 1069-1078, 1998 .

37. Adams JM and Cory S: Life-or-death decisions by the Bcl-2 protein family. Trends Biochem Sci 26: 61-66, 2001.

38. Datta SR, Brunet A and Greenberg ME: Cellular survival: a play in three akts. Genes Dev 13: 2905-2927, 1999.

39. Bahr C and Groner B: The insulin like growth factor-1 receptor (IGF-1R) as a drug target: Novel approaches to cancer therapy. Growth Horm IGF Res 14: 287-295, 2004.

40. Gronborg M, Wulff BS, Rasmussen JS, Kjeldsen T and Gammeltoft S: Structure-function relationship of the insulin-like growth factor-I receptor tyrosine kinase. J Biol Chem 268: 23435-23440, 1993.

41. Pawson T: Protein modules and signalling networks. Nature 373: 573-580, 1995

42. Sherr CJ and Roberts JM: CDK inhibitors: positive and negative regulators of G1-phase progression. Genes Dev 13: 1501-1512, 1999.

43. Stromberg T, Ekman S, Girnita L, et al: IGF-1 receptor tyrosine kinase inhibition by the cyclolignan PPP induces G2/M-phase accumulation and apoptosis in multiple myeloma cells. Blood 107: 669-678, 2006.

44. Gotlieb WH, Bruchim I, Gu J, et al: Insulin-like growth factor receptor I targeting in epithelial ovarian cancer. Gynecol Oncol 100: 389-396, 2006.

45. Mukohara T, Shimada H, Ogasawara N, et al: Sensitivity of breast cancer cell lines to the novel insulin-like growth factor-1 receptor (IGF-1R) inhibitor NVP-AEW541 is dependent on the level of IRS-1 expression. Cancer Lett 282: 14-24, 2009.

46. Ahmad T, Farnie G, Bundred NJ and Anderson NG: The mitogenic action of insulin-like growth factor I in normal human mammary epithelial cells requires the epidermal growth factor receptor tyrosine kinase. J Biol Chem 279: 1713-1719, 2004.

47. Gilmore AP, Valentijn AJ, Wang P, et al: Activation of bad by therapeutic inhibition of epidermal growth factor receptor and transactivation by insulin-like growth factor receptor. J Biol Chem 277: 27643-27650, 2002.

48. Nahta R, Yu D, Hung MC, Hortobagyi GN and Esteva FJ: Mechanisms of disease: understanding resistance to HER2targeted therapy in human breast cancer. Nat Clin Pract Oncol 3: 269-280, 2006

49. Carter TA, Wodicka LM, Shah NP, et al: Inhibition of drugresistant mutants of ABL, KIT, and EGF receptor kinases. Proc Natl Acad Sci USA 102: 11011-11016, 2005.

50. Norden AD, Young GS, Setayesh K, et al: Bevacizumab for recurrent malignant gliomas: efficacy, toxicity, and patterns of recurrence. Neurology 70: 779-787, 2008.

51. Li P, Nijhawan D, Budihardjo I, et al: Cytochrome c and dATPdependent formation of Apaf-1/caspase-9 complex initiates an apoptotic protease cascade. Cell 91: 479-489, 1997.

52. Eskes R, Desagher S, Antonsson B and Martinou JC: Bid induces the oligomerization and insertion of Bax into the outer mitochondrial membrane. Mol Cell Biol 20: 929-935, 2000.

53. Lynch TJ, Bell DW, Sordella R, et al: Activating mutations in the epidermal growth factor receptor underlying responsiveness of non-small-cell lung cancer to gefitinib. N Engl J Med 350: 2129-2139, 2004.

54. Mellinghoff IK, Wang MY, Vivanco I, et al: Molecular determinants of the response of glioblastomas to EGFR kinase inhibitors. N Engl J Med 353: 2012-2024, 2005.

55. Chakravarti A, Loeffler JS and Dyson NJ: Insulin-like growth factor receptor I mediates resistance to anti-epidermal growth factor receptor therapy in primary human glioblastoma cells through continued activation of phosphoinositide 3-kinase signaling. Cancer Res 62: 200-207, 2002. 